\title{
Congratulations to CHROMATOGRAPHIA's Editorial Advisory Board Award-Winning Members
}

\author{
André M. Striegel ${ }^{1}$
}

Published online: 3 March 2022

This is a U.S. government work and not under copyright protection in the U.S.; foreign copyright protection may apply 2022

A preeminent factor in the success of CHROMATOGRAPHIA is the Journal's outstanding Editorial Advisory Board (EAB). Comprised of a worldwide team of experts across the separation science spectrum, our EAB provides the Editors feedback on the direction of the journal, on areas of potential improvement, ideas for special issues and, of course, also contributes to the journal as both authors and reviewers. It is not an exaggeration to say that the Editors consider the $\mathrm{EAB}$ a sine qua non of our journal.

It is, thus, with great delight that we recognize here three members of our EAB who have recently been the recipients of various awards in the field of separation science: Professors Joe Foley and James Grinias and Dr. Imad Haidar Ahmad.

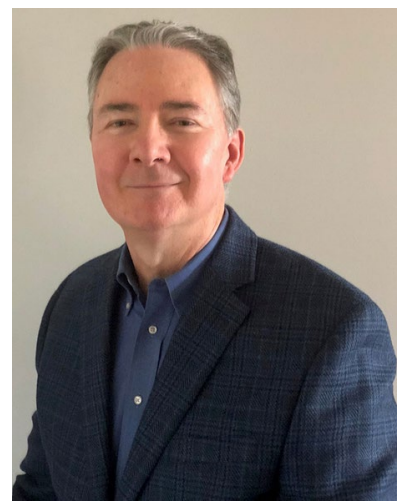

Joe Foley was recently the recipient of the 2021 Chromatography Forum of Delaware Valley (CFDV) Award. Joe is both Professor and Department Head of the Department of Chemistry at Drexel University. Joe's many

André M. Striegel

andre.striegel@nist.gov

Chemical Sciences Division, National Institute of Standards and Technology (NIST), 100 Bureau Drive, MS 8390,

Gaithersburg, MD 20899-8390, USA accomplishments in separation science include over 130 peer-reviewed publications, book chapters, tutorials, and patents; his mentoring of over 70 undergraduates, graduate students, post-docs and visiting scientists; his contributions in the area of chromatographic figures of merit, not least of which being the Foley-Dorsey equation, used to calculate critical parameters from tailed peaks employing an exponentially modified Gaussian model; his seminal contribution to our understanding of second-dimension sampling rate on peak resolution in two-dimensional liquid chromatography; and his numerous contributions to both theory and practice during the early days of micellar electrokinetic chromatography. More recently, his interest has turned to the hydrophobic subtraction model, tandem-column liquid chromatography, sequential elution liquid chromatography, and to stochastic simulations of UHPLC and CE separations. Joe's CFDV Award reflects both these and other achievements in separation science along with his longtime service to the CFDV in various capacities. Joe was also the recipient of the 2020 Eastern Analytical Symposium Award for Outstanding Achievements in Separation Science.

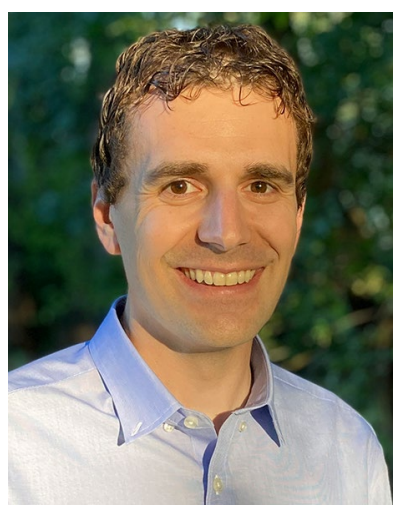

James (Jim) Grinias is the recipient of both the 2021 ACS Satinder Ahuja Young Investigator in Separation Science Award and the 2022 LCGC Emerging Leader in 
Chromatography Award. Both these awards recognize the achievements of young separation scientists early in their career. Jim is currently Associate Professor in the Department of Chemistry and Biochemistry at Rowan University. Jim's research focuses on the fundamental development of liquid chromatography (LC) columns in capillaries and microfluidic devices. He is also interested in understanding the physical processes beyond bed structure that impact column performance and in applying LC and mass spectrometry instrumentation to solve analytical problems in neuroscience and molecular physiology. Jim is currently chair-elect of the ACS Subdivision on Chromatography and Separations Chemistry and was also recipient of the 2020 Young Investigator Award of the Chinese American Chromatography Association. Jim is the author of 36 peerreviewed publications and was recognized by our journal in 2019 as one of the Rising Stars in Separation Science as part of CHROMATORAPHIA's 50th Anniversary Commemorative Issue.

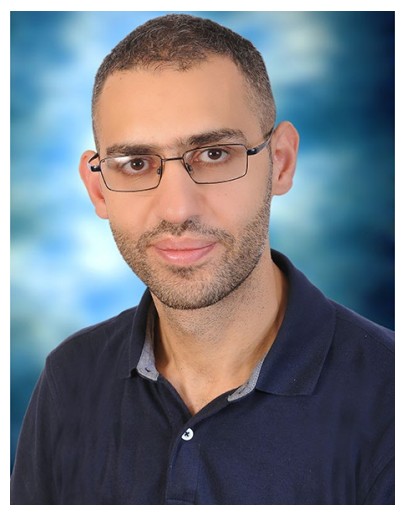

Imad Haidar Ahmad is recipient of the 2022 Young Investigator Award of the Chinese American Chromatography Association. The award recognizes outstanding contributions to the development of separation science and its applications, especially in the field of chromatography. Imad is currently Associate Principal Scientist and Scientific Supervisor for Analytical Chemistry Enabling Technologies in the R\&D Department at Merck. He is the author of 44 peer-reviewed publications, being first author on 23 of these. Imad is the rare expert on both fundamental and applied macromolecular and small-molecule separations, including multi-detector and two-dimensional techniques. His paper "Improved Synthesis of Carbon-Clad Silica Stationary Phases" (Analytical Chemistry 2013, 85:11,765) was selected as a top-ten in the field for 2013 by C\&EN and his work has made the cover of Analytical Chemistry four times. Imad was selected to CHROMATOGRAPHIA's inaugural class of Young Investigators in Separation Science; his papers in our journal have received more than 3400 downloads to date.

Congratulations to Joe, Jim, and Imad on having their contributions to separation science recognized by their respective awards!

Publisher's Note Springer Nature remains neutral with regard to jurisdictional claims in published maps and institutional affiliations. 